\title{
Variations in Stress Tolerance Abilities of Diverse Listeria monocytogenes Isolates
}

\author{
Satyajit B. Kale ${ }^{1,4}$, Nitin V. Kurkure', Swapnil P. Doijad², Krupali V. Poharkar ${ }^{3}$, \\ Sandeep Garg ${ }^{4}$, Deepak B. Rawool ${ }^{5}$ and Sukhadeo B. Barbuddhe ${ }^{3 *}$
}

\author{
${ }^{1}$ Department of Pathology, Nagpur Veterinary College, Maharashtra Animal and Fishery \\ Sciences University, Nagpur 440006, India \\ ${ }^{2}$ Institute of Medical Microbiology, Justus-Liebig University, 35392 Giessen, Germany \\ ${ }^{3}$ ICAR-National Institute of Biotic Stress Management, Baronda, Raipur, 493225, India \\ ${ }^{4}$ Department of Microbiology, Goa University, Taleigaon Plateau, Goa 403 206, India \\ ${ }^{5}$ Division of Veterinary Public Health, Indian Veterinary Research Institute, \\ Izatnagar, 243122, India \\ *Corresponding author
}

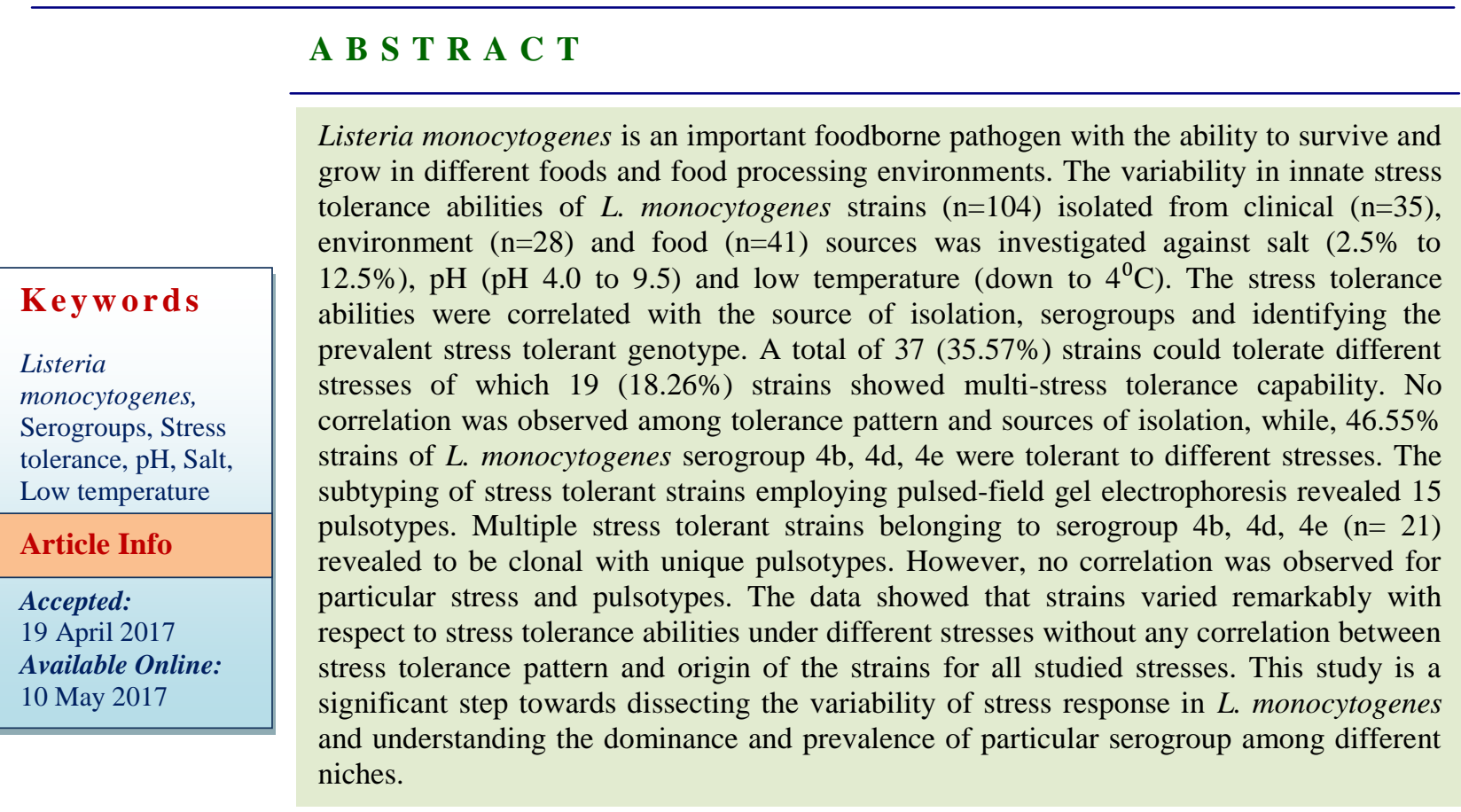

\section{Introduction}

Listeria monocytogenes, a Gram-positive, ubiquitous bacterium is a well known and important foodborne pathogen (Hoffmann et al., 2015). The extraordinary capabilities of the pathogen to survive in the gastrointestinal tract of animals and humans and its intracellular multiplication eventually can develop into a disease makes this bacterium a major concern (Olier et al., 2003; Cossart, 2012). Although the pathogen can infect 
healthy individuals, listeriosis is more common in immune-compromised individuals, pregnant women, neonates, elderly people, children, cancer patients and patients on immunosuppressive therapy (Silk et al., 2012; Feng et al., 2013). Listeriosis has $20-30 \%$ case fatality rate, $50 \%$ neonatal death rate and $91 \%$ hospitalization rate (Sartor et al., 2015). Being ubiquitous, $L$. monocytogenes easily enters in the food chain, contaminates foods and food processing environments. It has unique capabilities such as tolerance to high salt concentrations (as high as 10-14\%), low temperature (down to $0^{\circ} \mathrm{C}$ ) and diverse $\mathrm{pH}$ range (pH 4.5 to 9.5) (Buchanan et al., 2004; Gandhi and Chikindas, 2007) which make $L$. monocytogenes a versatile and pervasive in nature and also help to survive even in suboptimal environmental conditions (Shabala et al., 2008). Ironically, these abilities allow the pathogen to grow selectively in harsh conditions in food processing industries. Contaminated foods that are stored in a refrigerator $\left(4^{0} \mathrm{C}-7^{0} \mathrm{C}\right)$ enrich growth of $L$. monocytogenes making it difficult to control (Angelidis et al., 2002; Makariti et al., 2015).

Earlier studies reported large variations in stress tolerance of L. monocytogenes under different conditions of high salt, acidic and/or alkaline $\mathrm{pH}$ and low temperature (De Jesús and Whiting, 2006; Valero et al., 2014).

Limited studies have been done demonstrating the relation between stress tolerance and serotype or origin of isolation of L. monocytogenes. Numerous investigations are based on the physiological basis of stress tolerance, but most of these studies are available with a limited number of strains (Lianou et al., 2003; Liu et al., 2005, Vermeulen et al., 2007). This approach limits investigation for the comprehensive scenario for determination of variation in stress phenotypes under different stresses.
In order to control the spread of the pathogen, the stress tolerance mechanisms of $L$. monocytogenes have been a focus of research worldwide. Several universal stress mechanisms such as efflux pump also have been identified in L. monocytogenes, which help cells get adapted easily to low level stresses inducing tolerance capabilities (Romanova, 2006).

Indian Listeria Culture Collection (ILCC) has a large collection of strains of Listeria that have been isolated from various sources and diverse geographical areas of India. The objective of this study was to assess the innate capacity of $L$. monocytogenes, belonging to different serogroups and isolated from various sources to tolerate food-related stresses. Furthermore, the study attempted to the study attempted to correlate the stress tolerant strains with a source of isolation and serogroups identifying dominant serogroup with the particular genotype. In this study, 104 L. monocytogenes strains from ILCC of different origins representing the epidemiologically important serotypes were studied for their stress tolerance capacities using several food-related stresses.

\section{Materials and Methods}

\section{Listeria monocytogenes strains}

A total of 104 Listeria monocytogenes strains were selected from the Indian Listeria Culture Collection (ILCC). The collection comprised of the strains isolated from different geographical regions of India and from diverse sources such as human as well as animal clinical cases $(n=35)$, food processing and natural environment $(\mathrm{n}=28)$ and ready to eat (RTE) and raw foods $(n=41)$ (Table 1). All the strains were characterized previously biochemically and for their serogroups (Doumith et al., 2004). The L. monocytogenes strains were belonging to serogroups of $L$. 
monocytogenes as $4 \mathrm{~b}, 4 \mathrm{~d}, 4 \mathrm{e}(\mathrm{n}=58), 1 / 2 \mathrm{a}$, $1 / 2 \mathrm{c}, 3 \mathrm{a}, 3 \mathrm{c}(\mathrm{n}=34)$ and $1 / 2 \mathrm{~b}, 3 \mathrm{~b}, 4 \mathrm{~b}, 4 \mathrm{~d}, 4 \mathrm{e}$ $(n=12)$ considering their importance in foodborne outbreaks (Buchrieser et al., 1993). All the strains were maintained at $-80^{\circ} \mathrm{C}$ in brain heart infusion (BHI) broth (Himedia, India) with $15 \%$ sterile glycerol (v/v) (Himedia, India).

\section{Inocula preparation}

Listeria monocytogenes strains were cultured on PALCAM agar (Himedia, India) at $37^{\circ} \mathrm{C}$ for $24 \mathrm{~h}$. Single colony for each strain was inoculated in $10 \mathrm{ml}$ of BHI broth and incubated at $37^{\circ} \mathrm{C}$ for $18 \mathrm{~h}$. The cell densities of overnight grown culture were approximately $10^{9} \mathrm{CFU} / \mathrm{ml}$. The grown cultures were further diluted 1:100 with fresh BHI broth and used for inoculation in microplates.

\section{Salt tolerance}

Each strain was tested in duplicate for the salt tolerance in 96 well flat bottom microplates (GenAxy, India). BHI broth medium supplemented with additional sodium chloride (Himedia, India) concentrations of $0.5 \%$, $2.5 \%, 5 \%, 7.5 \%, 10 \%$ and $12.5 \%$ were prepared. Each well (containing media 190 $\mu \mathrm{L})$ was inoculated with $10 \mu \mathrm{L}$ of each diluted inocula. Plates were covered with sterile lid and then sealed with parafilm.

The duplicate sets were included for each salt concentration in each 96 well flat bottom microplates and a set of three plates was prepared for each experimental set-up. The inoculated plates were incubated at $37^{\circ} \mathrm{C}$ and growth was followed at $\mathrm{OD}_{600 \mathrm{~nm}}$ after $24 \mathrm{~h}, 48$ $\mathrm{h}$, and $72 \mathrm{~h}$ (Multiscan Ascent, Thermofisher, USA) and compared with two un-inoculated wells serving as negative controls. The purity of cultures was checked by cultivating on BHI agar at the end of the experiment.

\section{pH tolerance}

$\mathrm{BHI}$ broth was prepared with the $\mathrm{pH}$ range of 4.0 to 9.5 with the increments of $0.5 \mathrm{pH}$ units. The $\mathrm{pH}$ of the medium was adjusted using $1 \mathrm{~N}$ $\mathrm{HCl}$ (Merck, Germany) for acidic $\mathrm{pH}$ and $1 \mathrm{~N}$ $\mathrm{NaOH}$ (Merck, Germany) for alkaline $\mathrm{pH}$. Each well (containing media $190 \mu \mathrm{L}$ ) was inoculated with $10 \mu \mathrm{L}$ of each diluted inoculants and were incubated at $37^{\circ} \mathrm{C}$.The procedures were carried out as explained for salt tolerance experiments.

\section{Low temperature tolerance}

The inoculants of each $L$. monocytogenes strain were prepared as described earlier. Each strain was tested for its low temperature tolerance by inoculating in wells containing media $190 \mu \mathrm{L}$ for each strain in each 96 well flat bottom microplates in duplicate, and a set of three plates was prepared for each experimental set-up. The plates were incubated at $4^{\circ} \mathrm{C}, 10^{\circ} \mathrm{C}, 18^{\circ} \mathrm{C}, 24^{\circ} \mathrm{C}$ and $30^{\circ} \mathrm{C}$. The further observation procedures were carried as explained for salt tolerance experiments.

\section{Pulsed Field Gel Electrophoresis (PFGE)}

A total of 37 strains which exhibited tolerance at least one of the stress factors studied were further investigated for their genomic patterns using pulse field gel electrophoresis (PFGE). The PFGE was performed according to the Pulse Net standardized protocol (Graves and Swaminathan, 2001). In brief, bacterial cell suspension was embedded in $1.2 \%$ PFGE grade agarose (Bio-Rad, USA). The plugs were digested either with $25 \mathrm{U}$ of $A s c \mathrm{I}$ (New England BioLabs, Beverly, MA, USA) at $37^{\circ} \mathrm{C}$ for $3 \mathrm{~h}$ or $25 \mathrm{U}$ of ApaI (New England BioLabs, Beverly, MA, USA) at $25^{\circ} \mathrm{C}$ for $5 \mathrm{~h}$. After digestion the plugs were loaded on $1 \%$ PFGE grade agarose gel in $0.5 \mathrm{X}$ TBE buffer and electrophoresed on CHEF-DRIII Mapper 
apparatus (Bio-Rad Laboratories, Hercules, USA). The gel also loaded with Lambda ladder (New England Biolabs, Beverly, MA). The generated DNA fragments were separated using following electrophoresis conditions: voltage, $6 \mathrm{~V}$; initial switch time, 4.0s; final switch time $40 \mathrm{~s}$; runtime $19 \mathrm{~h}$ and temperature at $14^{0} \mathrm{C}$. After electrophoresis gel was stained for $30 \mathrm{~min}$ in $400 \mathrm{ml}$ of $0.5 \mathrm{x}$ TBE containing $25 \mathrm{ml}(10 \mathrm{mg} / \mathrm{ml})$ of ethidium bromide and destained by two washes of 20 min each using $400 \mathrm{ml}$ of deionized water and visualized under gel documentation system (Bio-Rad, USA). Genomic fingerprints were analyzed by Phoretix Software (Total labs, UK).

\section{Results and Discussion}

\section{Tolerance to different salt concentrations}

Listeria monocytogenes, a ubiquitous pathogen, has been reported to survive in different harsh conditions. Because of its ability to adapt to adverse environmental conditions, control of L. monocytogenes in food processing facilities is difficult task (Gandhi and Chikindas, 2007). It is well understood that L. monocytogenes have the extraordinary fitness to adapt diverse environmental conditions; including higher salinity, extreme $\mathrm{pH}$ and colder temperatures. We analyzed a total of 104 strains isolated from clinical sources $(n=35)$, food processing and natural environment $(n=28)$ and ready to eat (RTE) and raw foods $(n=41)$ belonging to three epidemiologically significant serogroups $4 \mathrm{~b}, 4 \mathrm{~d}, 4 \mathrm{e}(\mathrm{n}=58) ; 1 / 2 \mathrm{a}, 1 / 2 \mathrm{c}, 3 \mathrm{a}, 3 \mathrm{c}(\mathrm{n}=34)$ and $1 / 2 b, 3 b, 4 b, 4 d, 4 e(n=12)$ (Table S1). Strains exhibiting growth at $12.5 \% \mathrm{NaCl}$ concentration were considered as 'high' stress tolerant (Makarti et al., 2014). Out of 104 strains studied a total of $13(12.5 \%)$ strains were found to be tolerant up to $12.5 \%$ high salt concentration followed by $65(62.5 \%)$ strains tolerant to up to $10 \%$ salt concentration and all the strains showed tolerance up to $7.5 \%$ salt (Fig. 1a). Total $6(17.14 \%)$ strains from clinical cases, 5 (17.85\%) from environmental sources and $2(4.87 \%)$ from food were found to be tolerant to the high salt concentration. Salting is the indispensable method used in the manufacturing of many foods such as cheese types; it is also used as additive for flavoring and preservation (Lou and Yousef, 1997). The salt concentrations generally used in such procedures are inadequate for inhibiting the growth of $L$. monocytogenes. In this study, all test strains were assessed without any previous adaptive exposure to the any of these high salt concentrations. The results showed the innate high salt tolerance by $L$. monocytogenes strains. This capability of the pathogen may explain its ubiquitous nature through survival and adaptation to diverse environment from soil to a eukaryotic host with the capacity to tolerate hardy conditions (Freitag, 2009) and also supports the use of L. monocytogenes as a model for understanding the switching life as environmental bacterium to pathogen inside the human cell (Xayarath and Freitag, 2012). As percent tolerant strains from clinical and food sources are similar, and the percentage of strains from environmental sources is low, there was no any exact correlation observed for salt stress tolerance and source of isolation of the strains.

\section{pH tolerance}

Effect of diverse $\mathrm{pH}$ range (4.0 to 9.5 with an increment of 0.5 units) was studied on 104 isolates of L. monocytogenes. The strains showing growth at $\mathrm{pH} \leq 4.5$ or $\geq 9$ were considered as 'high' stress tolerant (Makarti et al., 2014). A total of 25 isolates were found to be tolerant to the extreme $\mathrm{pH}$ (acidic $=13$ and alkaline=12). Out of 104 strains tested 13 $(12.5 \%)$ strains showed growth at $\mathrm{pH} 4.5$, while, $76(73.07 \%)$ strains showed tolerance up to $\mathrm{pH} 5.0$ and all strains were tolerant up to 
pH 5.5 (Fig. 1b). While 12 (11.53\%) strains showed tolerance at $\mathrm{pH} 9.5$ and $70(67.3 \%)$ strains showed growth up to $\mathrm{pH} 9.0$. All the (Fig.1c) strains showed the tolerance up to $\mathrm{pH}$ 8.5. The tolerance exhibited by $L$. monocytogenes strains to the diverse $\mathrm{pH}$ range supported the earlier observations of incidence and persistence of the pathogen in different food processing facilities (Moorhead and Dyes 2004; Zang et al., 2011; Larsen et $a l$. , 2014) such as milk and/or cheese production facilities (Lomonaco et al., 2009; Doijad et al., 2015; Stessl et al., 2014), meat processing plants (Martin et al., 2014; Wang et al., 2015), seafood industry (Holch et al., 2013; Leong et al., 2014). This may partly explain the survival of the pathogen at extreme $\mathrm{pH}$ conditions in a host, like gastrointestinal environment (McClure et al., 1997). When considered with a source of isolation, total $7(17.07 \%)$ strains from food showed tolerance to each acidic and alkaline $\mathrm{pH}$. Surprisingly, only $1(3.57 \%)$ strain from environmental source found to be tolerant to acidic and alkaline $\mathrm{pH}$ stress. From clinical sources, 5(14.28\%) strains showed high tolerance to acidic $\mathrm{pH}$, while, $4(11.42 \%)$ strains were tolerant to high alkaline $\mathrm{pH}$.

\section{Tolerance to low temperature}

Considering varied temperature ranges used in processing, storage as well as the distribution of food products $\left(4^{\circ} \mathrm{C}, 10^{\circ} \mathrm{C}\right.$, $18^{\circ} \mathrm{C}, 24^{\circ} \mathrm{C}$, and $30^{\circ} \mathrm{C}$ ), tolerance was studied at different temperatures. The lowest temperature tested was $4^{\circ} \mathrm{C}$ selected as representative of domestic as well as retail refrigerators (Kennedy et al., 2005). The strains showing growth at $4^{\circ} \mathrm{C}$ were selected as highly tolerant strains to low temperature. Out of 104 strains tested a total of 22 $(21.15 \%)$ strains showed growth at $4^{\circ} \mathrm{C}$ and, whereas, $64(61.53 \%)$ showed growth at $10^{\circ} \mathrm{C}$ (Fig. 1d). While all the strains grew well at $18^{\circ} \mathrm{C}$ and above.
Storage at low temperature is extensively used method for food preservation at domestic, retail as well as industrial levels. In this study, the strains showed varied tolerance to low temperature. The maximum number of strains found to be highly tolerant to the low temperatures which are widely used for food storage, processing and/or distribution in industries as well as at domestic and retail levels. The temperatures at which $L$. monocytogenes found to be tolerant are unusual temperatures for a pathogenic bacterium. Many ready-to-eat foods such as milk, milk products are stored at these temperatures may permit the growth of $L$. monocytogenes to increase a load of pathogen thereby increasing chances of infection (Chan and Wiedmann, 2008). Modern food industries are attempting to minimize the use of food preservatives. Therefore, shelf life and food safety mainly rely on maintenance of the cold chain. Cold stress tolerance explains that ability to proliferate at lowtemperature benefits L. monocytogenes to overcome other pathogens in the environment or in food making it major food borne pathogen (Durack et al., 2013). Earlier findings revealed frequent linkage of industrially processed and refrigerated foods than raw foods to L. monocytogenes outbreaks (Gianfranceschi et al., 2002). Among the low temperature tolerant strains, $10 \quad(28.57 \%)$ strains were from clinical sources followed by $10(24.39 \%)$ from food and $2(7.14 \%)$ from the environment.

A total of $37(35.57 \%)$ strains were found to be tolerant to at least one of stress tested. Of these 16 strains were tolerant to more than one stress. Among the tolerant strains, $13(12.5 \%)$ strains were tolerant to high salt, $25(24.03 \%)$ to extreme $\mathrm{pH}$ and $22(21.15 \%)$ were tolerant to low temperature. When compared to their serotypes, $46.55 \%(27 / 58)$ serogroup $4 b \quad$ strains, $33.33 \% \quad(4 / 12)$ serogroup $1 / 2 b$ strains and $17.64 \%$ (6/34) 
serogroup $1 / 2$ a strains were found to be stress tolerant (Fig. 2). While comparing the sources of isolation, $18(51.52 \%)$ strains from clinical, 15 (36.58\%) from food and 5 (23.80\%) from environmental sources were found to be stress tolerant. Analyzing the percent tolerance with respect to a source of isolation for each stress of high salt, $\mathrm{pH}$ and low temperature, there was no exact correlation found among tolerance patterns and sources of isolation as observed earlier (Lianou et al., 2003). However, interestingly, serogroup $4 \mathrm{~b}$ strains were observed to be more stress tolerant than that of serogroup $1 / 2 \mathrm{~b}$ and $1 / 2 \mathrm{a}$. Earlier studies (van der Veen et al., 2008; Makarti et al., 2014) also observed a high number of serotype $4 \mathrm{~b}$ strains showing tolerance followed by serptype $1 / 2 \mathrm{~b}$ and $1 / 2 \mathrm{a}$ strains. This could be a possible explanation for the dominance of serotype $4 b$ in clinical cases.

\section{PFGE}

Analysis of whole genome patterns of 37 tolerant strains with both the enzymes (AscI and ApaI) revealed 15 pulsotypes (Fig. 3) Two strains could not be typed with the AscI enzyme. The Simpson's Diversity index was low (0.6873), indicating very few of strains were capable of tolerating the stress. The observed 15 pulsotypes were labeled serially and alphabetically from ' $A$ ' to ' $O$ '. The strains with pulsotype ' $M$ ' were observed to be dominant clustering 15 strains belonging to serogroup 4b. Apparently, the possibility of single ubiquitous stress tolerating $4 \mathrm{~b}$ clone cannot be denied. Also, in the case of serogroup $1 / 2 \mathrm{a}$ and $1 / 2 \mathrm{~b}$ strains very low genomic variation was noted. Although PFGE profiles showed correlation with the serotypes, there were no associations found with the stress tolerance capacities. Interestingly, the stress tolerance pattern of the similar pulsotype strains was different. For example, the strains with pulsotype ' $\mathrm{M}$ ' were found to tolerate variable $\mathrm{pH}$, salt, and low temperature. Similarly, in the case of serogroup $1 / 2 \mathrm{a}$ strains and $1 / 2 \mathrm{~b}$ strains were not consistent with their tolerance pattern.

Table.1 List of Listeria monocytogenes isolates used in this study

\begin{tabular}{|l|c|c|c|}
\hline ILCC ID & PCR serogrouping & Source & $\begin{array}{c}\text { Year of } \\
\text { Isolation }\end{array}$ \\
\hline ILCC001 & 4b, 4d, 4e & Food & 2006 \\
\hline ILCC003 & 4b, 4d, 4e & Animal & 2001 \\
\hline ILCC004 & 4b, 4d, 4e & Animal & 2001 \\
\hline ILCC006 & 4b, 4d, 4e & Animal & 2001 \\
\hline ILCC007 & 4b, 4d, 4e & Food & 2007 \\
\hline ILCC010 & 4b, 4d, 4e & Food & 2007 \\
\hline ILCC012 & $4 b, 4 d, 4 e$ & Food & 2007 \\
\hline ILCC013 & $4 b, 4 d, 4 e$ & Food & 2007 \\
\hline ILCC014 & 4b, 4d, 4e & Food & 2007 \\
\hline ILCC015 & 4b, 4d, 4e & Animal & 2001 \\
\hline ILCC016 & 4b, 4d, 4e & Animal & 2006 \\
\hline ILCC017 & 4b, 4d, 4e & Human & 2009 \\
\hline ILCC022 & 4b, 4d, 4e & Animal & 2001 \\
\hline ILCC025 & 4b, 4d, 4e & Animal & 2006 \\
\hline
\end{tabular}




\begin{tabular}{|c|c|c|c|}
\hline ILCC026 & $4 b, 4 d, 4 e$ & Human & 2006 \\
\hline ILCC028 & $4 \mathrm{~b}, 4 \mathrm{~d}, 4 \mathrm{e}$ & Human & 2006 \\
\hline ILCC029 & $1 / 2 b, 3 b, 4 b, 4 d, 4 e$ & Human & 2006 \\
\hline ILCC032 & $4 \mathrm{~b}, 4 \mathrm{~d}, 4 \mathrm{e}$ & Human & 2006 \\
\hline ILCC035 & $4 \mathrm{~b}, 4 \mathrm{~d}, 4 \mathrm{e}$ & Human & 2009 \\
\hline ILCC036 & $4 \mathrm{~b}, 4 \mathrm{~d}, 4 \mathrm{e}$ & Human & 2005 \\
\hline ILCC037 & $4 \mathrm{~b}, 4 \mathrm{~d}, 4 \mathrm{e}$ & Human & 2005 \\
\hline ILCC038 & $4 \mathrm{~b}, 4 \mathrm{~d}, 4 \mathrm{e}$ & Human & 2005 \\
\hline ILCC040a & $4 \mathrm{~b}, 4 \mathrm{~d}, 4 \mathrm{e}$ & Animal & 2001 \\
\hline ILCC042 & $4 \mathrm{~b}, 4 \mathrm{~d}, 4 \mathrm{e}$ & Animal & 2006 \\
\hline ILCC043 & $4 b, 4 d, 4 e$ & Animal & 2006 \\
\hline ILCC045 & $4 \mathrm{~b}, 4 \mathrm{~d}, 4 \mathrm{e}$ & Animal & 2007 \\
\hline ILCC051a & $1 / 2 a, 1 / 2 c, 3 a, 3 c$ & Animal & 2002 \\
\hline ILCC142 & $4 \mathrm{~b}, 4 \mathrm{~d}, 4 \mathrm{e}$ & Human & 2005 \\
\hline ILCC145a & $4 \mathrm{~b}, 4 \mathrm{~d}, 4 \mathrm{e}$ & Animal & 2005 \\
\hline ILCC146 & $4 \mathrm{~b}, 4 \mathrm{~d}, 4 \mathrm{e}$ & Animal & 2005 \\
\hline ILCC148 & $1 / 2 a, 1 / 2 c, 3 a, 3 c$ & Animal & 2005 \\
\hline ILCC149a & $4 \mathrm{~b}, 4 \mathrm{~d}, 4 \mathrm{e}$ & Animal & 2005 \\
\hline ILCC150a & $4 \mathrm{~b}, 4 \mathrm{~d}, 4 \mathrm{e}$ & Animal & 2005 \\
\hline ILCC152 & $1 / 2 \mathrm{a}, 1 / 2 \mathrm{c}, 3 \mathrm{a}, 3 \mathrm{c}$ & Food & 2004 \\
\hline ILCC158 & $4 \mathrm{~b}, 4 \mathrm{~d}, 4 \mathrm{e}$ & Food & 2006 \\
\hline ILCC161 & $4 \mathrm{~b}, 4 \mathrm{~d}, 4 \mathrm{e}$ & Food & 2006 \\
\hline ILCC171 & $4 \mathrm{~b}, 4 \mathrm{~d}, 4 \mathrm{e}$ & Animal & 2006 \\
\hline ILCC173 & $4 \mathrm{~b}, 4 \mathrm{~d}, 4 \mathrm{e}$ & Animal & 2006 \\
\hline ILCC174a & $1 / 2 a, 1 / 2 c, 3 a, 3 c$ & Animal & 2006 \\
\hline ILCC175a & $4 \mathrm{~b}, 4 \mathrm{~d}, 4 \mathrm{e}$ & Environmental & 2002 \\
\hline ILCC176 & $4 \mathrm{~b}, 4 \mathrm{~d}, 4 \mathrm{e}$ & Environmental & 2002 \\
\hline ILCC177a & $4 \mathrm{~b}, 4 \mathrm{~d}, 4 \mathrm{e}$ & Environmental & 2002 \\
\hline ILCC179 & $4 \mathrm{~b}, 4 \mathrm{~d}, 4 \mathrm{e}$ & Environmental & 2002 \\
\hline ILCC183 & $4 \mathrm{~b}, 4 \mathrm{~d}, 4 \mathrm{e}$ & Environmental & 2002 \\
\hline ILCC185 & $1 / 2 a, 1 / 2 c, 3 a, 3 c$ & Food & 2008 \\
\hline ILCC187 & $4 \mathrm{~b}, 4 \mathrm{~d}, 4 \mathrm{e}$ & Food & 2008 \\
\hline ILCC190 & $4 \mathrm{~b}, 4 \mathrm{~d}, 4 \mathrm{e}$ & Food & 2008 \\
\hline ILCC192 & $1 / 2 \mathrm{a}, 1 / 2 \mathrm{c}, 3 \mathrm{a}, 3 \mathrm{c}$ & Food & 2008 \\
\hline ILCC195 & $4 \mathrm{~b}, 4 \mathrm{~d}, 4 \mathrm{e}$ & Food & 2008 \\
\hline ILCC196a & $1 / 2 a, 1 / 2 c, 3 a, 3 c$ & Food & 2005 \\
\hline ILCC264 & $4 \mathrm{~b}, 4 \mathrm{~d}, 4 \mathrm{e}$ & Food & 2008 \\
\hline ILCC265 & $4 \mathrm{~b}, 4 \mathrm{~d}, 4 \mathrm{e}$ & Food & 2008 \\
\hline ILCC266 & $4 \mathrm{~b}, 4 \mathrm{~d}, 4 \mathrm{e}$ & Food & 2008 \\
\hline ILCC267 & $4 \mathrm{~b}, 4 \mathrm{~d}, 4 \mathrm{e}$ & Food & 2008 \\
\hline ILCC269 & $4 \mathrm{~b}, 4 \mathrm{~d}, 4 \mathrm{e}$ & Food & 2008 \\
\hline ILCC270 & $4 \mathrm{~b}, 4 \mathrm{~d}, 4 \mathrm{e}$ & Food & 2008 \\
\hline ILCC 272 & $4 \mathrm{~b}, 4 \mathrm{~d}, 4 \mathrm{e}$ & Food & 2008 \\
\hline ILCC 273 & $4 \mathrm{~b}, 4 \mathrm{~d}, 4 \mathrm{e}$ & Food & 2008 \\
\hline ILCC 274 & $4 \mathrm{~b}, 4 \mathrm{~d}, 4 \mathrm{e}$ & Food & 2008 \\
\hline
\end{tabular}




\begin{tabular}{|c|c|c|c|}
\hline ILCC276 & $4 \mathrm{~b}, 4 \mathrm{~d}, 4 \mathrm{e}$ & Animal & 2001 \\
\hline ILCC277 & $4 \mathrm{~b}, 4 \mathrm{~d}, 4 \mathrm{e}$ & Food & 2008 \\
\hline ILCC279 & $4 \mathrm{~b}, 4 \mathrm{~d}, 4 \mathrm{e}$ & Food & 2008 \\
\hline ILCC285 & $1 / 2 b, 3 b, 4 b, 4 d, 4 e$ & Food & 2004 \\
\hline ILCC289 & $1 / 2 b, 3 b, 4 b, 4 d, 4 e$ & Food & 2004 \\
\hline ILCC293 & $1 / 2 b, 3 b, 4 b, 4 d, 4 e$ & Food & 2004 \\
\hline ILCC297 & $1 / 2 b, 3 b, 4 b, 4 d, 4 e$ & Food & 2004 \\
\hline ILCC298 & $1 / 2 b, 3 b, 4 b, 4 d, 4 e$ & Food & 2004 \\
\hline ILCC301a & $1 / 2 b, 3 b, 4 b, 4 d, 4 e$ & Food & 2004 \\
\hline ILCC302a & $1 / 2 b, 3 b, 4 b, 4 d, 4 e$ & Food & 2004 \\
\hline ILCC303a & $1 / 2 b, 3 b, 4 b, 4 d, 4 e$ & Food & 2004 \\
\hline ILCC304a & $1 / 2 b, 3 b, 4 b, 4 d, 4 e$ & Food & 2004 \\
\hline ILCC305 & $1 / 2 b, 3 b, 4 b, 4 d, 4 e$ & Food & 2004 \\
\hline ILCC312 & $1 / 2 \mathrm{a}, 1 / 2 \mathrm{c}, 3 \mathrm{a}, 3 \mathrm{c}$ & Food & 2004 \\
\hline ILCC317 & $1 / 2 \mathrm{a}, 1 / 2 \mathrm{c}, 3 \mathrm{a}, 3 \mathrm{c}$ & Food & 2007 \\
\hline ILCC325 & $1 / 2 \mathrm{a}, 1 / 2 \mathrm{c}, 3 \mathrm{a}, 3 \mathrm{c}$ & Food & 2007 \\
\hline ILCC373 & $1 / 2 \mathrm{a}, 1 / 2 \mathrm{c}, 3 \mathrm{a}, 3 \mathrm{c}$ & Environmental & 2010 \\
\hline ILCC374 & $1 / 2 \mathrm{a}, 1 / 2 \mathrm{c}, 3 \mathrm{a}, 3 \mathrm{c}$ & Environmental & 2010 \\
\hline ILCC 375 & $1 / 2 \mathrm{a}, 1 / 2 \mathrm{c}, 3 \mathrm{a}, 3 \mathrm{c}$ & Environmental & 2010 \\
\hline ILCC376 & $1 / 2 \mathrm{a}, 1 / 2 \mathrm{c}, 3 \mathrm{a}, 3 \mathrm{c}$ & Environmental & 2010 \\
\hline ILCC377 & $1 / 2 a, 1 / 2 c, 3 a, 3 c$ & Environmental & 2010 \\
\hline ILCC378 & $1 / 2 \mathrm{a}, 1 / 2 \mathrm{c}, 3 \mathrm{a}, 3 \mathrm{c}$ & Environmental & 2010 \\
\hline ILCC479 & $4 \mathrm{~b}, 4 \mathrm{~d}, 4 \mathrm{e}$ & Food & 2008 \\
\hline ILCC494 & $4 \mathrm{~b}, 4 \mathrm{~d}, 4 \mathrm{e}$ & Animal & 2006 \\
\hline ILCC496 & $4 \mathrm{~b}, 4 \mathrm{~d}, 4 \mathrm{e}$ & Environmental & 2002 \\
\hline ILCC521 & $1 / 2 \mathrm{a}, 1 / 2 \mathrm{c}, 3 \mathrm{a}, 3 \mathrm{c}$ & Environmental & 2010 \\
\hline ILCC529 & $1 / 2 \mathrm{a}, 1 / 2 \mathrm{c}, 3 \mathrm{a}, 3 \mathrm{c}$ & Environmental & 2010 \\
\hline ILCC530 & $1 / 2 \mathrm{a}, 1 / 2 \mathrm{c}, 3 \mathrm{a}, 3 \mathrm{c}$ & Environmental & 2010 \\
\hline ILCC619 & $4 \mathrm{~b}, 4 \mathrm{~d}, 4 \mathrm{e}$ & Human & 2013 \\
\hline ILCC622 & $1 / 2 b, 3 b, 4 b, 4 d, 4 e$ & Human & 2013 \\
\hline ILCC624 & $4 \mathrm{~b}, 4 \mathrm{~d}, 4 \mathrm{e}$ & Human & 2013 \\
\hline ILCC629 & $1 / 2 \mathrm{a}, 1 / 2 \mathrm{c}, 3 \mathrm{a}, 3 \mathrm{c}$ & Human & 2013 \\
\hline ILCC767 & $1 / 2 \mathrm{a}, 1 / 2 \mathrm{c}, 3 \mathrm{a}, 3 \mathrm{c}$ & Environmental & 2013 \\
\hline ILCC768 & $1 / 2 a, 1 / 2 c, 3 a, 3 c$ & Environmental & 2013 \\
\hline ILCC769 & $1 / 2 \mathrm{a}, 1 / 2 \mathrm{c}, 3 \mathrm{a}, 3 \mathrm{c}$ & Environmental & 2013 \\
\hline ILCC770 & $1 / 2 \mathrm{a}, 1 / 2 \mathrm{c}, 3 \mathrm{a}, 3 \mathrm{c}$ & Environmental & 2013 \\
\hline ILCC771 & $1 / 2 \mathrm{a}, 1 / 2 \mathrm{c}, 3 \mathrm{a}, 3 \mathrm{c}$ & Environmental & 2013 \\
\hline ILCC772 & $1 / 2 \mathrm{a}, 1 / 2 \mathrm{c}, 3 \mathrm{a}, 3 \mathrm{c}$ & Environmental & 2013 \\
\hline ILCC773 & $1 / 2 \mathrm{a}, 1 / 2 \mathrm{c}, 3 \mathrm{a}, 3 \mathrm{c}$ & Environmental & 2013 \\
\hline ILCC774 & $1 / 2 \mathrm{a}, 1 / 2 \mathrm{c}, 3 \mathrm{a}, 3 \mathrm{c}$ & Environmental & 2013 \\
\hline ILCC775 & $1 / 2 a, 1 / 2 c, 3 a, 3 c$ & Environmental & 2013 \\
\hline ILCC776 & $1 / 2 \mathrm{a}, 1 / 2 \mathrm{c}, 3 \mathrm{a}, 3 \mathrm{c}$ & Environmental & 2013 \\
\hline ILCC777 & $1 / 2 \mathrm{a}, 1 / 2 \mathrm{c}, 3 \mathrm{a}, 3 \mathrm{c}$ & Environmental & 2013 \\
\hline ILCC778 & $1 / 2 \mathrm{a}, 1 / 2 \mathrm{c}, 3 \mathrm{a}, 3 \mathrm{c}$ & Environmental & 2013 \\
\hline ILCC779 & $1 / 2 a, 1 / 2 c, 3 a, 3 c$ & Environmental & 2013 \\
\hline
\end{tabular}


Fig.1 (a) The percentage of salt stress tolerant strains to the different salt concentrations. (b) The percentage of low $\mathrm{pH}$ stress tolerant strains to respective acidic $\mathrm{pH}$. (c) The percentage of high $\mathrm{pH}$ stress tolerant strains to respective alkaline $\mathrm{pH}$. (d) The percentage of cold stress tolerant strains at different low temperatures

Fig.1
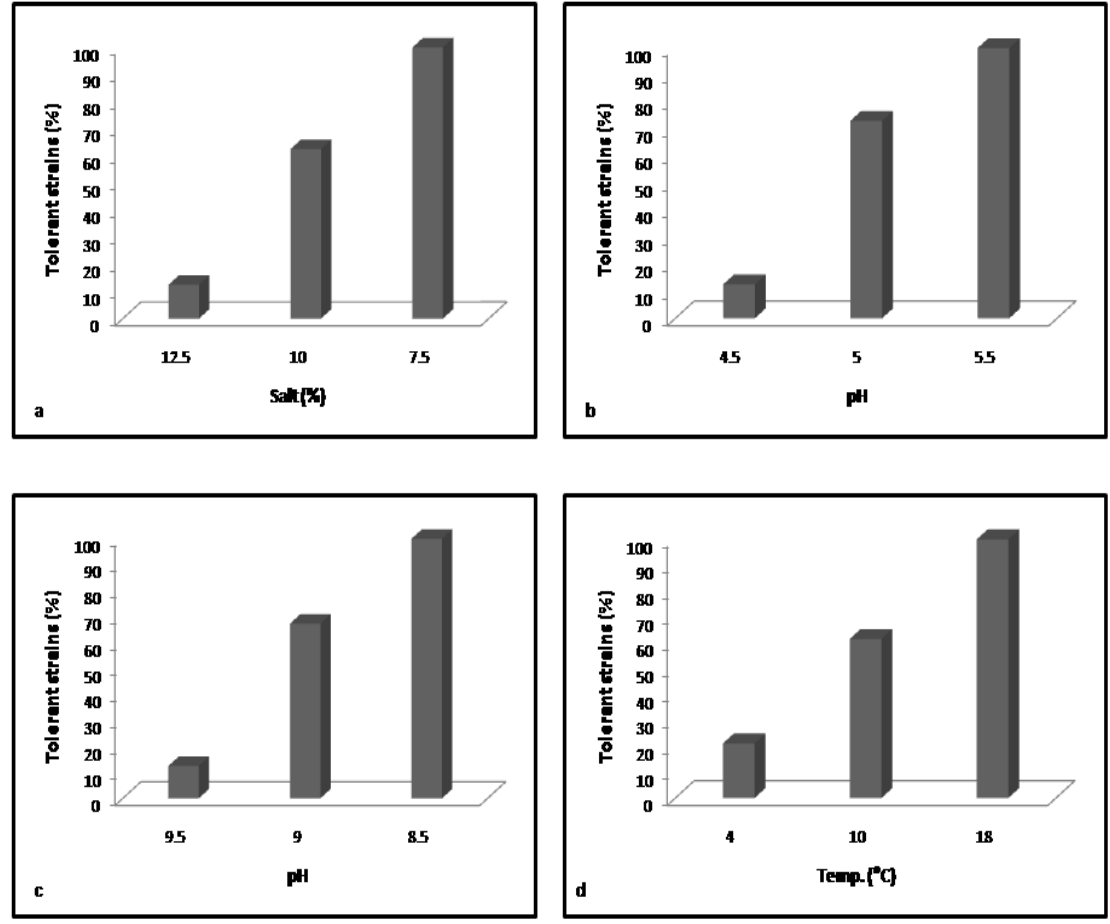

Fig.2 Stress tolerance pattern of the strains with respect to serotypes

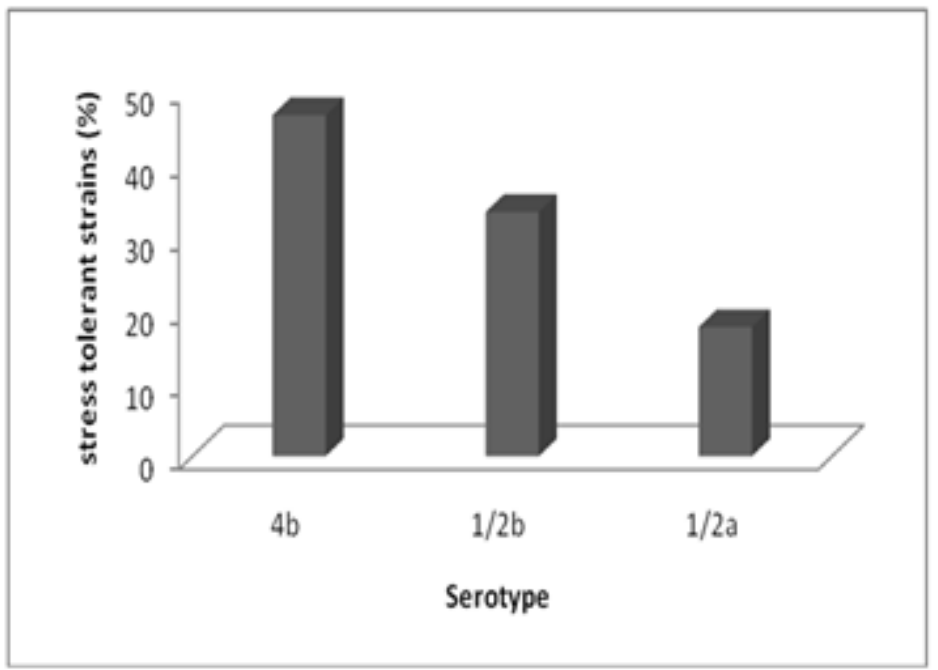


Fig.3 Dendrogram (UPGMA) showing PFGE patterns of 37 stress tolerant Listeria monocytogenes strains restricted by AscI and ApaI enzymes with dtails of the source of isolation, serotype and stress tolerance patterns

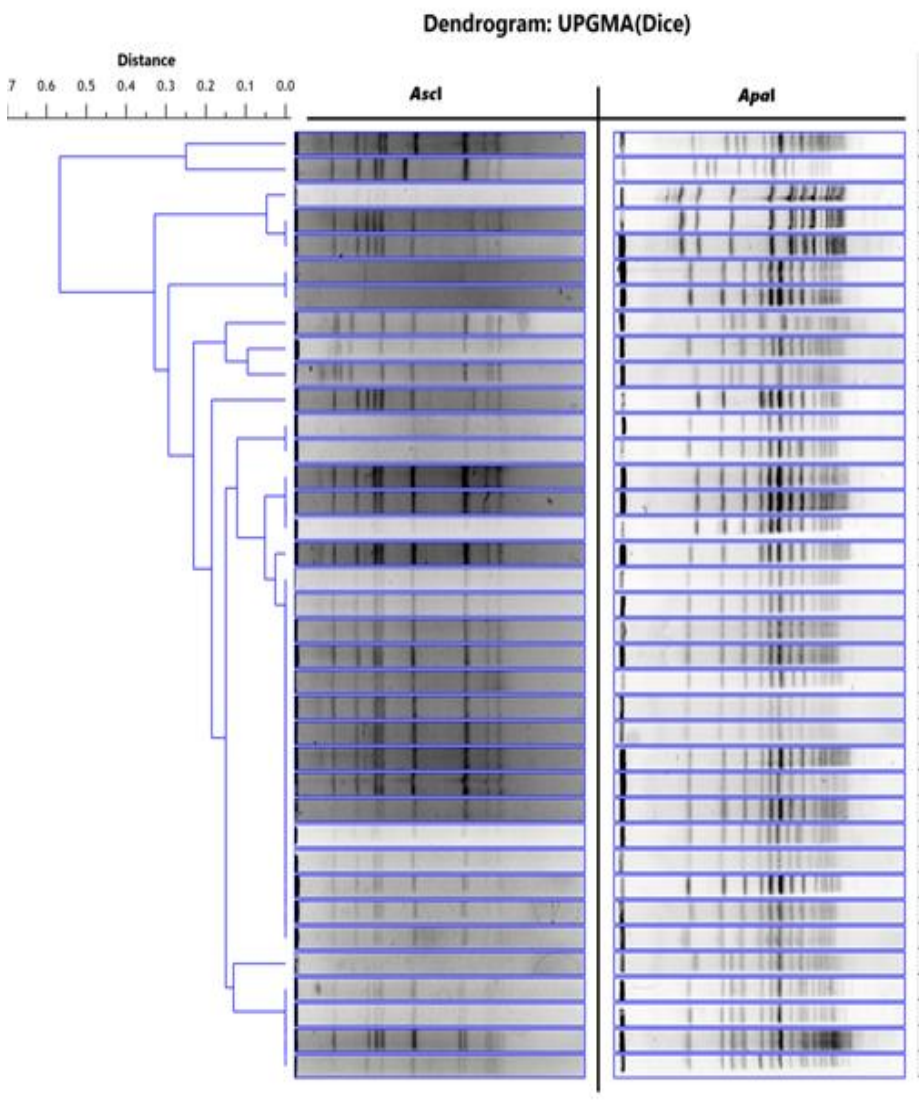

\begin{tabular}{|c|c|c|c|c|c|c|c|c|c|c|}
\hline IICC & & Year & Place & $\begin{array}{c}\text { PCR } \\
\text { Serogrouping }\end{array}$ & $\begin{array}{l}\text { Source } \\
\text { Broas }\end{array}$ & $\begin{array}{l}\text { Source. } \\
\text { Subsourte }\end{array}$ & Source- Specimas & pll & $\begin{array}{l}\text { Salt } \\
\text { (\%) }\end{array}$ & $\begin{array}{l}\text { Lor } \\
\text { Teap. } \\
\text { (C)) }\end{array}$ \\
\hline ICCIIS & $A$ & & Mulbe & ab.48, in & Inviremental & Potaly & Poutiny & 50.95 & 125 & 4 \\
\hline IICosis & 8 & & Manbe & ab. 44,4 & Munun & Cont & Crined & 50.90 & 10 & 4 \\
\hline ILCosy & c & & Soltherur & $1 / 2,12 x_{2}, k$ & Invwonmental & 对 & Food inturenid enveroment & 50.90 & 125 & 10 \\
\hline $\mathrm{HCCl}$ & \multirow{2}{*}{ D } & & & $12 a, 12 x$ is 22 & Arind & tropprns & W24 & 50.95 & 125 & 4 \\
\hline Hocom & & & Kolhigu & 12alkeks & Envoromintal & va & 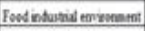 & 50.90 & 125 & 10 \\
\hline $\mathrm{HCCO}$ & \multirow{2}{*}{$\mathrm{t}$} & $2 m$ & Nespar & 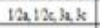 & Food & Vegrection & Vegreatites & 50.90 & 10 & 4 \\
\hline necoss & & 椡 & $x_{\operatorname{mog}}$ & ab, 24 ite & Food & Vegrtith & Pegretibs & 50.90 & 125 & 4 \\
\hline$\pi \cos 24$ & $\boldsymbol{I}$ & & Manbi & ab. 44 in & Minan & Chotal & Ginced & 45.90 & 10 & 18 \\
\hline Hoctus & 6 & & Kalbigur & ab. $44,4 \mathrm{se}$ & Anted & $A=4$ & Anind & 50.90 & 10 & 4 \\
\hline IICosin & 县 & & & ab, sd in & Hinan & $\tan$ & Bann & 45.90 & 10 & 4 \\
\hline thocy & 1 & & Kothera & Vialize bese & Envionmentat & 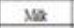 & 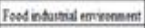 & 45.95 & 125 & 10 \\
\hline Hecsoss & \multirow{2}{*}{$\mathrm{J}$} & & Napere & ab, 84,4 & Food & $x / 2$ & $\mathrm{y} x$ & 50.90 & 10 & 4 \\
\hline $\mathrm{nocm}$ & & & Xogere & ab. 44.4 & Foed & 漹 & $\mathrm{xa}$ & 50.90 & 10 & 4 \\
\hline Hecoss & \multirow{3}{*}{$\mathrm{E}$} & & Napper & ab, 48,4 & Iood & va & ve & 40.90 & 75 & 10 \\
\hline noes & & $m$ & Sopper & ab. 4 ath & Tood & $x$ & va & 45.95 & 10 & 4 \\
\hline $10 \cos x$ & & 2033 & & ab, 484 & Hown & $\operatorname{Hax}$ & $\operatorname{Ban}$ & 50.95 & 10 & 10 \\
\hline Hocts & $\mathrm{t}$ & 到 & Nogper & ab. $48, \mathrm{in}$ & 10004 & Vegrathen & Vegredites & 45.95 & 10 & 4 \\
\hline ICOCOI & \multirow{15}{*}{ st } & 200 & $\mathrm{Cos}$ & ab, 44 the & Food & Mest & Xen & 40.95 & 75 & 10 \\
\hline $1 \mathrm{HCOOH}$ & & & INI & 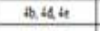 & Anesed & Aninat & Annald & 45.90 & 125 & 4 \\
\hline $\mathrm{HCOA2}$ & & 20 & Muabus & ab. 44 4h & Hinan & $\operatorname{man}$ & $\ln =$ & 50.90 & 125 & 4 \\
\hline Incels & & 2005 & Yuaber & ab. 44.6 & Anes & Anat & Aneat & 50.95 & 125 & 10 \\
\hline Hoclus & & 3 & Muabui & Ab, 44,4 & Anent & Anive & Areat & 50.90 & 10 & 4 \\
\hline 110015 & & & & ab, $44 \mathrm{~h}$ & Anead & $A=1$ & Anind & 45.90 & 10 & 10 \\
\hline ICCl6! & & 30 & $\mathrm{Cos}$ & 46, 48 in & Food & Met & Nent & 45.90 & 10 & 10 \\
\hline Hecis & & 湔 & Yogper & th. 44 in & Food & Pegraten & Vegrethes & 50.90 & 125 & 4 \\
\hline I $\cos s \theta$ & & & Yosper & Ab. $41+4$ & Foed & 19 & $\mathrm{x}$ & 45.95 & 75 & 10 \\
\hline ICCON & & & $\mathrm{Xgpe}$ & the.46, in & Food & ya & ve & 45.95 & 10 & 10 \\
\hline Itcoss & & & & ab. 44.4 & Aneal & Axprape & WZAY & 50.90 & 10 & 4 \\
\hline $11 \cos s$ & & & $\mathrm{Am}$ & ab. 44.4 & Hum & ham & himin & 50.90 & 10 & 4 \\
\hline Ilcotos & & & & Ab, 44 , in & Axind & Aned & Aned & 45.95 & 10 & 18 \\
\hline ILCCLO & & & & Ab 44,4 & Asenat & Aned & $A_{n=1}$ & 50.9 .0 & 10 & 4 \\
\hline Hociss & & & Yanbe & the 44 th & Eavionment & Puby & Poutry & 50.90 & 123 & 10 \\
\hline Hocis: & $\mathrm{s}$ & 34 & Whatbe & $12,12 \mathrm{k} k \mathrm{k}$ & Food & Yeet & Shat & 50.90 & 10 & 4 \\
\hline nocews & \multirow{4}{*}{0} & W & Manbe: & $18,36,06,14,46$ & food & $x 2$ & $\sqrt{x a}$ & 50.9 .93 & 10 & 4 \\
\hline ICCNY & & $m$ & Minbui & $1.58,36,36,14$ at & Food & $x=$ & 82 & 50.95 & 73 & 4 \\
\hline $\mathrm{HCOCO2}$ & & & Minabe & $120,36,4 b, 4 a, 4 t$ & Plum & Const & Cancal & 50.90 & 125 & 18 \\
\hline Incoss & & 36 & Pendethros: & ab. 44 th & Hunan & $\operatorname{Hax}$ & him & 50.90 & 125 & 4 \\
\hline
\end{tabular}

Considering the clonal or narrow genetic profile of the strains exhibiting tolerance to different stresses, it can be inferred that these tolerances must have been controlled by some common factor. Those common factors could be the presence some genes playing a role in survival and adaptation during exposure to the stressful environment. In-silico bioinformatics analysis of L. monocytogenes whole genomes have suggested several such gene-clusters present at distinct regions of the genome that altogether play significant roles in stress tolerance. All these gene-clusters, however, appear to be controlled by a single factor known as sigB (Kazmierczak et al., 2003; Hain et al., 2008). Further studies are necessary to confirm this hypothesis. $L$. monocytogenes is normally exposed to various stresses during food processing and disinfection procedures which could influence its response and ability to persist in these environments and thus contributes to defining conditions for better control in food processing plants (Magalhaes et al., 2016).

It is reported that the innate resistance by $L$. monocytogenes strains to the stresses commonly employed in food preservation and/or food processing. The data showed that strains varied remarkably with respect to stress tolerance abilities under different stresses. There was no correlation observed between stress tolerance pattern and origin of the strains for all stresses. The investigation underlined significant stress tolerance by serogroup 4b, 4d, 4e strains. This could be a 
possible explanation for the dominance of serotype 4b, 4d, 4e strains among clinical cases. This improved our understanding that how specific strains or subtypes of $L$. monocytogenes become resident to selected niches. PFGE analysis showed clonal or less genetic diversity among the stress tolerant strains. This study is a significant step towards dissecting the variability of stress response in $L$. monocytogenes and understanding the dominance and prevalence of particular serogroup among different niches.

\section{Acknowledgements}

The research work is supported by grants from the Department of Biotechnology, Government of India (BT/01/CEIB/11/VI/13) to SBB and NVK. There are no conflicts of interests to declare.

\section{References}

Angelidis, A.S., Smith, L.T., et al. 2002. Elevated carnitine accumulation by Listeria monocytogenes impaired in glycine betaine transport is insufficient to restore wild-type cryotolerance in milk whey. Int. J Food Microbiol., 75 (1-2):19.

Buchanan, R., Lindqvist, R., 2004. Risk assessment of Listeria monocytogenes in ready-to-eat foods. Microbiological Risk Assessment Series, 4. Food and Agriculture Organization of the United Nations

Buchrieser, C., Brosch, R., et al. 1993. Pulsedfield gel electrophoresis applied for comparing Listeria monocytogenes strains involved in outbreaks. Can J Microbiol., 39 (4):395-401.

Chan, Y.C., Wiedmann, M. 2008. Physiology and Genetics of Listeria monocytogenes Survival and Growth at Cold Temperatures. Crit Rev Food Sci Nutr., 49(3):237-253.
Cossart, P. 2012. Illuminating the landscape of host-pathogen interactions with the bacterium Listeria monocytogenes. Proc Natl Acad Sci USA., 108(49):1948419491.

De Jesús, A.J. and Whiting, R.C. 2006. Thermal inactivation, growth and survival studies of Listeria monocytogenes strains belonging to three distinct genotypic lineages. J Food Prot., 66(9):1611-1617.

Doijad, S.P., Barbuddhe, S.B., et al. 2011. Incidence and genetic variability of Listeria species from three milk processing plants. Food Cont., 22(11): 1900-1904

Doumith, M., Buchrieser, C., et al. 2004. Differentiation of the major Listeria monocytogenes serovars by multiplex PCR. J Clin Microbiol., 42(8):3819-3822.

Durack, J., Ross, T., et al. 2013. Characterisation of the transcriptomes of genetically diverse Listeria monocytogenes exposed to hyperosmotic and low temperature conditions reveal global stress-adaptation mechanisms. PLoS One., 8(9): e73603.

Feng, Y., Wu S., et al. 2013. Systematic review of human listeriosis in China, 1964-2010. Trop Med Int Health., 18:1248-1256.

Freitag, N.E. 2009. Complete transcriptional profile of an environmental pathogen. Future Microbiol., 4:779-782

Gandhi, M., and Chikindas, M.L. 2007. Listeria: a foodborne pathogen that knows how to survive. Int $J$ Food Microbiol., 113:1-15.

Gianfranceschi, M., Gattuso, A., et al. 2002. Incidence of Listeria monocytogenes in food and environmental samples in Italy between 1990 and 1999: Serotype distribution in food, environmental and clinical samples. Eur J Epidemiol., 18:1001-1006.

Graves, L.M. and Swaminathan, B. 2001. PulseNet standardized protocol for subtyping Listeria monocytogenes by macrorestriction and pulsed-field gel electrophoresis. Int J Food Microbiol., 
65: 55-62.

Hain, T., Hossain, H., et al. 2008. Temporal transcriptomic analysis of the Listeria monocytogenes EGD-e $\sigma^{\mathrm{B}}$ regulon. BMC Microbiol., 28:8- 20.

Hoffmann, S., Bryan, M., et al. 2015. Economic Burden of Major Foodborne Illnesses Acquired in the United States, EIB-140, U.S. Department of Agriculture, Economic Research Service.

Holch, A., Webb, K., et al. 2013. Genome sequencing identifies two nearly unchanged strains of persistent Listeria monocytogenes isolated at two different fish processing plants sampled 6 years apart. Appl Environ Microbiol., 79:29442951.

Kazmierczak, M.J., Mithoe, S.C., et al. 2003. Listeria monocytogenes sigma $B$ regulates stress response and virulence functions. $J$ Bacteriol., 185:5722-5734.

Kennedy, J., Jacksonm, V., et al. 2005. Food safety knowledge of consumers and the microbiological and temperature status of their refrigerators. J Food Prot., 68:14211430.

Larsen, M.H., Dalmasso, M., et al. 2014. Persistence of foodborne pathogens and their control in primary and secondary food production chains, Food Cont., 44:92-109.

Leong, D., Alvarez-Ordóñez, A., et al. 2014. Monitoring occurrence and persistence of Listeria monocytogenes in foods and food processing environments in the Republic of Ireland. Front Microbiol., 20:436.

Lianou, A., Stopforth, J.D., et al. 2003. Growth and stress resistance variation in culture broth among Listeria monocytogenes strains of various serotypes and origins, J Food Prot., 69:2640-2547.

Liu, D., Lawrence, M.L., et al. 2005. Comparative assessment of acid, alkali and salt tolerance in Listeria monocytogenes virulent and avirulent strains. FEMS Microbiol Lett., 243:373378.

Lomonaco, S., Decastell, L., et al., 2009. Listeria monocytogenes in Gorgonzola: subtypes, diversity and persistence over time. Int J Food Microbiol., 128:516-520.

Lou, Y., and Yousef, A.E. 1997. Adaptation to sublethal environmental stresses protects Listeria monocytogenes against lethal preservation factors. Appl Environ Microbiol., 63:1252-1255.

Magalhaes, R., Ferreira, V., et al. 2016. Persistent and non-persistent strains of Listeria monocytogenes: A focus on growth kinetics under different temperature, salt, and $\mathrm{pH}$ conditions and their sensitivity to sanitizers. Food Microbiol., 57(8):103-108.

Makariti, I.P., Printezi, A., et al. 2015. Investigating boundaries of survival, growth and expression of genes associated with stress and virulence of Listeria monocytogenes in response to acid and osmotic stress. Food Microbiol., 45(2):1-14.

Martin, B., Perich, A., et al. 2014. Diversity and distribution of Listeria monocytogenes in meat processing plants. Food Microbiol 44(12): 119-127.

McClure, P.J., Beaumont, A.L., et al. 1997. Predictive modelling of growth of Listeria monocytogenes: The effects on growth of $\mathrm{NaCl}, \mathrm{pH}$, storage temperature and NaNO2. Int J Food Microbiol., 34: 221-232.

Moorhead, S.M. and Dyes, G.A. 2004. Influence of the $\operatorname{sig} \mathrm{B}$ gene on the cold stress survival and subsequent recovery of two Listeria monocytogenes serotypes. Int $J$ Food Microbiol., 91: 63-72.

Olier, M., Pierre, F., et al. 2003. Expression of truncated internalin is involved in impaired internalization of some Listeria monocytogenes isolates carried asymptomatically by humans. Infect Immun., 71:1217-1224.

Romanova, N.A., Wolffs, P.F., et al. 2006. Role of efflux pumps in 
adaptation and resistance of Listeria

monocytogenes to benzalkonium chloride. Appl Environ Microbiol., 72:3498-503.

Sartor, C., Grégoire, E., et al. 2015. Invasive Listeria monocytogenes infection after liver transplantation: a lifethreatening condition. Lancet., 6736:61831-61836.

Shabala, L., Lee, S.H., et al. 2008. Acid and $\mathrm{NaCl}$ limits to growth of Listeria monocytogenes and influence of sequence of inimical acid and $\mathrm{NaCl}$ levels on inactivation kinetics. J Food Prot., 71: 1169-1177.

Silk. B. J., Date, K. A., et al. 2012. Invasive listeriosisin the Foodborne Diseases Active Surveillance Network (FoodNet), 2004-2009: further targeted prevention needed for higher-riskgroups. Clin Infec Dis., 54:396-404.

Stessl, B., Fricker, M., et al. 2014. Collaborative survey on the colonization of different types of cheese-processing facilities with Listeria monocytogenes. Foodborne Pathog Dis., 11:8-14.

Valero, A., Hernandez, M., et al. 2014. Survival kinetics of Listeria

monocytogenes on raw sheep milk cured cheese under different storage temperatures. Int $J$ Food Microbiol., 184:39-44

van der Veen, S., Moezelaar, R., et al. 2008. The growth limits of a large number of Listeria monocytogenes strains at combinations of stresses show serotype-and niche-specific traits. $J$ Appl Microbiol., 105:1246-1258.

Vermeulen, A., Gysemans, K.P., et al. 2007. Influence of $\mathrm{pH}$, water activity and acetic acid concentration on Listeria monocytogenes at $7^{\circ} \mathrm{C}$ : data collection for the development of a growth / no growth model, Int $J$ Food Microbiol., 114(3):332-341.

Wang, G.Y., Qian, W.J., et al. 2015. Prevalence, genetic diversity and antimicrobial resistance of Listeria monocytogenes isolated from ready-to-eat meat products in Nanjing, China. Food Cont., 50(4):202-208.

Xayarath, B. and Freitag, N.E. 2012. Optimizing the balance between host and environmental survival skills: lessons learned from Listeria monocytogenes. Future Microbiol., 7(7):839-752.

Zhang, Q., Feng, Y., et al. 2011. SigB plays a major role in Listeria monocytogenes tolerance to bile stress. Int J Food Microbiol 145(1): 238-243.

\section{How to cite this article:}

Satyajit B. Kale, Nitin V. Kurkure, Swapnil P. Doijad, Krupali V. Poharkar, Sandeep Garg, Deepak B. Rawool and Sukhadeo B. Barbuddhe. 2017. Variations in Stress Tolerance Abilities of Diverse Listeria monocytogenes Isolates. Int.J.Curr.Microbiol.App.Sci. 6(5): 2246-2258. doi: https://doi.org/10.20546/ijcmas.2017.605.250 